\title{
CONSEQUENNCIAS DO REASSENTAMENTO NO ENTOR- NO DA CONSTRUÇÃO DA USINA HIDROELÉTRICA DE SANTO ANTÔNIO: O CASO DO REASSENTAMENTO NOVO ENGENHO VELHO, EM PORTO VELHO/RO-BRASIL
}

\author{
Amarildo Pinheiro Virgulino* \\ Gleimiria Batista da Costa** \\ Oleides Francisca de Oliveira*** \\ Joel Bombardelli*****
}

\begin{abstract}
Resumo
Este artigo apresenta as consequências do reassentamento Novo Engenho Velho no Estado de Rondônia, no entorno da construção da Usina de Santo Antônio, oferecendo uma proposta metodológica para formação de recursos humanos para a qualidade de vida dos assentados. $\mathrm{O}$ trabalho realiza uma discussão sobre território como configuração espacial, e a ocupação local de 31 famílias que foram remanejadas de seu habitar - comunidade ribeirinha - formando uma Agrovila. A pesquisa foi desenvolvida a partir do estudo de caso, aplicado questionário semiestruturado, com perguntas fechadas, a partir do qual se obteve $100 \%$ de retorno das entrevistas. O instrumento foi dividido em três dimensões de sustentabilidade: social, ambiental e econômica. Dentre os resultados encontrados, o que se destacou entre as três dimensões foi o de sustentabilidade social, com grau relevante, apresentado pelo indicador taxa de desemprego, justificando assim, a necessidade de qualificar e treinar esta comunidade para as ofertas de trabalho com renda que irão surgir em novas ocupações. Como solução para as consequências identificadas é proposta a metodologia de Capacitação Massiva, com desenvolvimento de atividades pertinentes à região.
\end{abstract}

Palavras-Chave: Reassentamento. Usina Hidroelétrica. Território. Metodologia de Capacitação Massiva.

\footnotetext{
* Mestre em Desenvolvimento Regional na Universidade Federal de Rondônia - UNIR/RO.Técnico da Comissão Executiva do Plano da Lavoura Cacaueira-CEPLAC.E-mail: amarildo-ro@ceplac.gov.br. ** Doutora em Desenvolvimento Regional. Professora do Curso de Ciências Contábeis da Universidade Federal de Rondônia-UNIR. E-mail: gleimiria@unir.br.

**** Doutora em Desenvolvimento Regional. Professora do Curso de Ciências Contábeis da Universidade Federal de Rondônia-UNIR. E-mail: oleides@yahoo.com.br.

***** Mestre em Engenharia da Produção. Professor do Curso de Ciências Contábeis da Universidade Federal de Rondônia-UNIR. E-mail: jbombardelli@globo.com.
} 


\section{Introdução}

O estado de Rondônia localiza-se na floresta amazônica, maior floresta tropical do mundo, o que tornam mais complexas as negociações para implementação de programas e seus projetos de desenvolvimento, crescimento e instalação de quaisquer empreendimentos que provocam impactos sociais, econômicos, ambientais e culturais. A fragilidade e rica biodiversidade de seus ecossistemas e seu peso no equilíbrio climático global, entre outros fatores, exigem precauções singulares para intervenções de alto potencial impactante na região (MORET, 2006).

O município de Porto Velho é parte deste contexto. Seu crescimento desordenado, o desmatamento, a baixa qualidade de vida, a ausência da infraestrutura necessária, a pressão sobre as terras indígenas, a desigualdade social, a vulnerabilidade de parte da população, entre outros fatores, compõem o cenário com o qual já convive sua população. $\mathrm{O}$ impacto da construção das Usinas Hidroelétricas - UHE do Rio Madeira pode acarretar o aumento proporcional dos problemas estruturais já existentes, representando um enorme desafio para a configuração de políticas sociais claras e eficazes que fortaleçam o seu território (COELHO, 2006).

Neste artigo pretende-se descrever o contexto territorial do reassentamento Novo Engenho Velho/RO, apresentando as consequências deste considerando as necessidades de uma comunidade ribeirinha que fora remanejada de seu habitat. Ali detinham sua sobrevivência com terras férteis, para o plantio de frutas regionais e mandioca para a produção da farinha, o feijão de praia, como também utilizavam o rio Madeira para a pesca, e a caça de animais silvestres para sua alimentação, para uma localidade adversa aos seus hábitos e costumes.

Para análise deste estudo foi utilizada a metodologia de estudo de caso aplicando um questionário semiestruturado abrangendo as três dimensões de sustentabilidade: social, ambiental e econômica. $\mathrm{O}$ estudo traz como problema a seguinte indagação: qual alternativa plausível de atividade produtiva geradora de renda foi oferecida à comunidade dos assentados no Novo Engenho Velho/RO?

A justificativa do trabalho é propor para estudo - diante dos dados da pesquisa de campo, pela coleta de dados do questionário, aplicado às 31 famílias desta localidade, em que apresenta as 
consequências sofridas por essas famílias do reassentamento -, a aplicação de uma metodologia de qualificação profissional.

Com resultado e análise deste levantamento, o estudo apresentou uma proposta metodológica, conhecida como Capacitação Massiva, que vem propor a qualificação de mãode-obra em outras atividades, que poderão ser oferecidas pela estrutura no novo habitar.

$\mathrm{O}$ artigo se estrutura a partir de um referencial teórico que versa sobre: Território na Configuração Espacial, apresentando como subtópico as Migrações e Sociedade Local; na sequencia o material e método com a Caracterização da Área de Estudo e o Reassentamento Novo Engenho Velho. Diante do material teórico e da pesquisa de campo, foram elaboradas pelos autores figuras ilustrativas demonstrando uma avaliação por indicadores em três dimensões: social, ambiental e econômica. Finalizando o artigo, apresentou-se os resultados da pesquisa com um diagnóstico da necessidade de aplicação de uma metodologia de qualificação profissional no novo habitar.

A investigação ora realizada buscou de forma referenciada propor e informar as ações sustentáveis de suporte a implementação de programas e projetos de desenvolvimento, principalmente na Amazônia brasileira, com enfoque no reassentamento Novo Engenho Velho, em Porto Velho - Rondônia, que contemplem o saber local num processo metodológico de capacitação massiva.

\section{Território como configuração espacial}

A configuração territorial, no começo da história do homem, segundo Santos (2002), é simplesmente o conjunto dos complexos naturais. À medida que a história vai se fazendo, a configuração territorial é dada pelas obras dos homens: estradas, plantações, casas, depósitos, portos, fábricas, cidades, dentre outras, verdadeiras próteses, criando-se uma configuração territorial que é cada vez mais o resultado de uma produção histórica e tende a uma negação da natureza natural, substituindo por uma natureza inteiramente humanizada.

Segundo Virgulino (2008), o contexto territorial não pode ser considerado neutro nesse processo de implementação de programas e projetos, mas, também na criação de uma modalidade de gestão integrada e sustentada. Mesmo que os diversos recursos naturais estejam relacionados ao espaço das mais diversas formas, 
se pode avançar sobre a noção de espaço de gestão de um recurso para designar a escala espacial sobre a qual se concebe e se coloca em ação uma dinâmica de execução. $\mathrm{O}$ espaço deve viabilizar a implantação de um programa global visando à melhoria do potencial de recursos já existentes. No caso dos recursos renováveis e humanos, esta noção permite a análise da estruturação do saber local, ecológica e geográfica do território.

Nesse sentido, torna-se necessário reconhecer que essa configuração, em parceria com vetores tecnológicos, possa ser um método ou modelo de conversão de paradigma, mas longe de se constituir em alavanca ideológica de um posicionamento do Estado no sentido de assumir diretamente a responsabilidade pelo patrimônio natural e formação de recursos humanos que se interagem. Nesse caso, viabiliza a relação de negociação simétrica entre diferentes atores que se sentem comprometidos pela evolução de um lugar ou de um sistema. E, isto só se torna possível ao se pressupor que todos esses atores sejam portadores de uma visão e de interesses patrimoniais, mesmo se tais interesses forem diferenciados (SIENA, 2002; VIRGULINO, 2008).

\section{Migrações e sociedade local}

A articulação do processo de colonização agrícola no Brasil iniciou-se primeiramente com a Revolução de 1930. Tal processo buscava a distribuição de terras a trabalhadores nacionais com o intuito de melhorar e gerar oportunidades à vida de humanos, e fixá-los objetivando a produção agrícola induzida pelo Estado e que vem marcar definitivamente a grande virada no Brasil contemporâneo por meio da transição de uma sociedade agrária para uma sociedade urbano-industrial. Verifica-se, no entanto, a passagem de uma política de imigração, que utiliza as populações estrangeiras para fins de colonização para uma política de orientação das migrações externas e de colonização em proveito das populações nacionais (MILITÃO, 2005).

Essa colonização, que poderia ser por meio do gerenciamento público ou privado, objetivando povoar de forma organizada os vazios demográficos, definiu-se como sendo: "colonizar é promover a fixação do elemento humano ao solo, o aproveitamento econômico da região e a elevação do nível de vida, saúde, instrução e preparo técnico dos habitantes das zonas rurais”, mas isso só poderia acontecer se promovesse a interação 
dos principais seguimentos com igualdade de esforços na mesma direção (VIRGULINO, 2008).

É interessante salientar que não devemos confundir reforma agrária com colonização. Que se objetive, visando a transferência dos camponeses para áreas distintas das que habitam, mas que se realize com a fixação do homem no lugar onde more. Segundo Santos (1993), isso era um alerta aos problemas que existiam na colonização na Amazônia.

Em Rondônia não foi diferente e, por meio de incentivos governamentais ocupou seu espaço, sem se preocupar com os impactos infraestruturais no âmbito: socioeconômico, ambiental e cultural, pois o saber local, que já havia se miscigenado, inicialmente por populações nordestinas em busca de pedras preciosas, migrantes, nacionais e estrangeiros, nos ciclos da borracha, deflagrando-se ao mesmo tempo na construção da estrada de ferro Madeira Mamoré, objetivando facilitar a logística de escoamento da borracha à Bolívia - país fronteiriço, não foi considerado na implementação desses programas (VIRGULINO, 2008).

Em momento algum se identificou uma política de formação de recursos humanos nesses programas de colonização e de ocupação de espaços em Rondônia. Somente na década de 1980, com a implementação e operacionalização do Programa de Desenvolvimento da Região Noroeste do Brasil - POLONOROESTE é que se visualizou, na implantação de Núcleos de Apoio ao Setor Rural - NUARES, o dimensionamento físico de laboratório de capacitação, como suporte a execução das políticas agrícolas constante no mesmo arcabouço do programa. Todavia, não foi eficiente e nem eficaz, pois se concentrou somente na divulgação e na formação de técnicos extensionistas para compor o quadro funcional da instituição de Assistência Técnica e Extensão Rural - ATER de suporte (VIRGULINO, 2008).

Nessa direção e como suporte sustentável, a metodologia da capacitação massiva,vem ao encontro do que presenciamos atualmente com a construção UHE do Rio Madeira, como alternativa plausível de qualificação profissional para o emprego ou mais propriamente, à ocupação da mão de obra em atividades produtivas geradoras de renda, oferece uma das soluções para a difícil equação qualificação emprego. Há mais de duas décadas se vem difundido e aplicando a metodologia de geração de emprego e rendas em áreas de pobreza, preocupando-se prioritariamente em preparar pessoas para enfrentar o drama do desemprego (MORAIS, 2001). 
Um dos pilares da metodologia de capacitação massiva é a autogestão. As pessoas das comunidades envolvidas nos projetos que utilizam tal metodologia são convidadas a criar seus espaços simbólicos de participação e organização, o que se inicia, geralmente com a escolha dos cursos a serem realizados. Antes que os participantes se integrem aos Laboratórios Organizacionais de Terreno (LOT), outra das bases da metodologia, durante um ou dois dias, em assembleia, é decidido que rumo darão à própria formação e capacitação profissional. Os laboratórios, no caso da capacitação, que costumam durar entre 30 e 50 dias, têm por orientação o gerenciamento das atividades práticas provenientes dos cursos de capacitação eleitos (MORAIS, 2001).

Este gerenciamento, e aqui está outro pilar, dá-se por meio da organização em grupos, que tem por meta a criação de um espírito associativo e cooperativo, o que no mais das vezes, faz nascerem associações e cooperativas que geram emprego e renda aos seus associados. Para consolidar as atividades práticas, segundo Morais (2001), é criada uma organização imaginária, contudo, trata-se de uma empresa real na parte material. As pessoas aprendem desta forma, a "não só a produzir, mas também a gerir uma empresa, desde a produção, comercialização e gerenciamento". Deflagrase, então, em reafirmar o caráter construtivista da metodologia, ao mencionar que o método baseia-se no aprender fazendo (PEREIRA, 2002).

O pressuposto metodológico é que as pessoas têm potencialidades e que as comunidades pobres dispõem de recursos humanos e materiais não utilizados que podem ser mobilizados para a criação de atividades produtivas e/ou o fortalecimento das já existentes, inseridas em um contexto de desenvolvimento local e sustentável; que organização não se ensina, mas se constrói a partir de uma vivência concreta por meio da inserção das pessoas em um processo de participação social, no qual se pratica a autogestão, possibilitando a elevação dos níveis de consciência (ingênua e crítica) da coletividade para o nível de consciência organizacional, a qual permite, de forma organizada, identificar seus problemas e limitações, suas causas e alternativas de soluções, assumindo-se, portanto, como sujeito de seu próprio desenvolvimento - condição indispensável para a transformação da realidade em que vivem (ARAÚJO, 2001).

REVISTA GRIFOS - N. 32/33 - 2012 


\section{Reassentamento Novo Engenho Velho}

A agrovila de Novo Engenho Velho foi o primeiro reassentamento concluído nos primeiros meses de 2009, por conta da construção do canteiro de obras da UHE de Santo Antônio. Nessa agrovila se dá o teste decisivo da impermeabilidade do empreendimento às reivindicações e necessidades das comunidades ribeirinhas afetadas. Essa comunidade está localizada à margem esquerda do Rio Madeira, na vazante da cachoeira de Santo Antônio, distante de Porto Velho aproximadamente cinco quilômetros, quando o acesso é feito pelo porto do Cai n’Água. $\mathrm{E}$ a oito quilômetros, dos quais um por água (travessia do rio), quando o acesso é por Santo Antônio, margem direita do Rio Madeira, local da investigação científica.

O Reassentamento Novo Engenho Velho é caracterizado pelo sistema de agrovila, no qual áreas residenciais e produtivas localizam-se em pontos distintos. A vila residencial foi composta por casas habitadas por famílias anteriormente residentes na área requerida para construção do canteiro de obras da UHE Santo antônio, motivo pelo qual, tanto o desenvolvimento físico da comunidade, como as ações de remanejamento ocorreram em momento anterior aos demais reassentamentos (PLENU'S, 2010).

As residências possuem estrutura em alvenaria em metragens que variam de $45 \mathrm{~m}^{2}$ a $100 \mathrm{~m}^{2}$ com área média de $2.000 \mathrm{~m}^{2}$. Essa variação decorre das características de origem.

Das 31 famílias provenientes da antiga comunidade de Engenho Velho possuem, além da moradia lotes de produção com área média de 3,2 ha.

As cinco famílias oriundas da comunidade de São Domingos receberam a mesma estrutura de moradias quando optaram para serem realocados no reassentamento, e somente três receberam lotes destinados à produção.

Compondo a agrovila, além da área residencial, há 21 (vinte e um) lotes de produção agrícola, medindo em média 3,5 (três e meio) ha destinados de acordo com as especificações e características observadas originariamente. Além desses lotes, outros 03 (três) compõem o espaço, sendo 01 (um) destinado área de demonstração agronômica e 02 (dois) lotes de reserva legal, totalizando 24 (vinte e quatro) lotes. O reassentamento possui também estruturas comunitárias, como: centro comunitário, casa de farinha, porto flutuante, igrejas, campo de futebol e praça. 


\section{Metodologia}

O método da pesquisa compreendeu a análise do contexto dos grandes programas de desenvolvimento, como o de Aceleração do Crescimento que abrange a construção de UHE e suas interferências nas diversas sociedades existentes nessas áreas potenciais. O local de investigação contempla as sociedades (comunidades) tradicionais no alto Rio Madeira, que por meio de questionários aplicados na coleta de dados, realizadas com as 31 famílias que habitam o reassentamento Novo Engenho Velho. Sendo o $1^{\circ}$ nível: Compilatório (coleta de dados e tabulações); $2^{\circ}$ nível: o Correlativo (comparação de dados); $3^{\circ}$ nível; Semântico (Cruzamento e obtenção de dados); $4^{\circ}$ nível: o Normativo (geração de produtos), que possibilita a análise de todos os itens anteriores, e a partir destes materiais, avaliar resultados e gerar conclusões.

A metodologia utilizada neste estudo atendeu as seguintes características: quanto à natureza é aplicada, a abordagem do problema é de forma quali-quanti, os instrumentos e técnicas de pesquisa utilizados foram por meio de questionário semiestruturado. Quanto aos fins da pesquisa caracteriza-se como descritiva, tendo como base o estudo de campo, que de acordo com Siena (2007), é realizado por dados levantados em um determinado grupo ou comunidade.

A pesquisa foi realizada com 31 famílias oriundas de uma comunidade ribeirinha (moravam às margens do Rio Madeira) próxima a Cachoeira de Santo Antônio, distante da cidade de Porto Velho aproximadamente cinco quilômetros, onde o acesso é feito pelo porto do Cai n’Água.

Os procedimentos metodológicos obedeceram como norteador das ações de pesquisa a precisão de cada indicador investigado, priorizando as dimensões: sociais, econômicas e ambientais, apresentados ao fornecimento de mão de obra por serem relevantes no contexto da formação de recursos humanos, na qualificação profissional dos reassentados do Novo Engenho Velho/RO.

\section{Análise e discussão dos resultados}

A situação das famílias atingidas e remanejadas para o Reassentamento Novo Engenho Velho em decorrência do projeto de construção da UHE de Santo Antônio, apresentaram os seguintes indicadores demonstrados e analisados no quadro 1 e gráficos 01 a 07. 
Quadro 1: Indicadores de Desenvolvimento Sustentável em três dimensões: social, econômica e ambiental, do entorno da UHE de Santo Antônio - Rio Madeira

\begin{tabular}{|c|c|c|c|c|c|}
\hline \multirow{2}{*}{$\begin{array}{l}\text { Vertente } \\
\text { Principal }\end{array}$} & \multirow[t]{2}{*}{ Elementos } & \multirow[t]{2}{*}{ Indicador } & \multicolumn{3}{|c|}{ Grau de Ocorrência } \\
\hline & & & Alta & Média & Baixa \\
\hline \multicolumn{6}{|c|}{ SUSTENTABILIDADE SOCIAL } \\
\hline \multirow{4}{*}{ Equidade } & \multirow[t]{3}{*}{$\begin{array}{l}\text { De pobre- } \\
\text { za }\end{array}$} & $\begin{array}{l}\text { \% população vivendo } \\
\text { abaixo/linha de pobreza }\end{array}$ & & $\mathrm{X}$ & \\
\hline & & $\begin{array}{lcc}\text { Índice } & \text { GINI } \\
\text { iniquidade incômoda }\end{array}$ & & $\mathrm{X}$ & \\
\hline & & Taxa de desemprego & & & $\mathrm{X}$ \\
\hline & De gênero & $\begin{array}{l}\text { Razão da média do salário } \\
\text { feminino/ salário mascu- } \\
\text { lino }\end{array}$ & & & $\mathrm{X}$ \\
\hline \multirow{8}{*}{ Saúde } & $\begin{array}{c}\text { Nutricio- } \\
\text { nal }\end{array}$ & $\begin{array}{l}\text { Situação Nutricional das } \\
\text { crianças }\end{array}$ & $\mathrm{X}$ & & \\
\hline & \multirow{2}{*}{$\begin{array}{l}\text { Mortali- } \\
\text { dade }\end{array}$} & $\begin{array}{l}\text { Coeficiente de mortalida- } \\
\text { de até cinco anos de idade }\end{array}$ & & & $\mathrm{X}$ \\
\hline & & $\begin{array}{l}\text { Expectativa de vida ao } \\
\text { nascer. }\end{array}$ & $\mathrm{X}$ & & \\
\hline & $\begin{array}{l}\text { Saneamen- } \\
\text { to }\end{array}$ & $\begin{array}{l}\text { \% população com dispo- } \\
\text { sitivos de esgotamento } \\
\text { sanitário }\end{array}$ & $\mathrm{X}$ & & \\
\hline & $\begin{array}{c}\text { Água } \\
\text { potável }\end{array}$ & $\begin{array}{l}\text { \% população com acesso à } \\
\text { água tratada. }\end{array}$ & $\mathrm{X}$ & & \\
\hline & \multirow{3}{*}{$\begin{array}{l}\text { Distri- } \\
\text { buição da } \\
\text { Atenção á } \\
\text { Saưde }\end{array}$} & $\begin{array}{l}\text { \% população com acesso } \\
\text { às unidades de atenção } \\
\text { primária à saúde }\end{array}$ & $\mathrm{X}$ & & \\
\hline & & $\begin{array}{l}\text { Imunização contra doen- } \\
\text { ças infecciosas infantis }\end{array}$ & & $\mathrm{X}$ & \\
\hline & & $\begin{array}{l}\text { Coeficiente de prevalência } \\
\text { contraceptiva }\end{array}$ & $\mathrm{X}$ & & \\
\hline \multirow{4}{*}{ Educação } & \multirow[t]{2}{*}{$\begin{array}{l}\text { Nível de } \\
\text { educação }\end{array}$} & $\begin{array}{l}\text { Percentagem das crianças } \\
\text { fora da escola fundamen- } \\
\text { tal com } 05 \text { anos de duração }\end{array}$ & & & $\mathrm{X}$ \\
\hline & & $\begin{array}{l}\text { Nível de educação média } \\
\text { (secundária) entre adultos }\end{array}$ & & & $\mathrm{X}$ \\
\hline & $\begin{array}{l}\text { Alfabetiza- } \\
\text { ção }\end{array}$ & $\begin{array}{l}\text { Taxa de analfabetismo de } \\
\text { adultos }\end{array}$ & & $\mathrm{X}$ & \\
\hline & Escolas & $\begin{array}{l}\text { Número de escolas exis- } \\
\text { tentes }\end{array}$ & & $\mathrm{X}$ & \\
\hline Moradia & $\begin{array}{l}\text { Condições } \\
\text { adequadas }\end{array}$ & $\begin{array}{l}\text { Área construída de moradia } \\
\text { por pessoa. }\end{array}$ & $\mathrm{X}$ & & \\
\hline Segurança & Crime & $\begin{array}{l}\text { Número de crimes registra- } \\
\text { dos por grupos de } 100.000 \\
\text { pessoas. }\end{array}$ & & & $\mathrm{X}$ \\
\hline \multirow{2}{*}{ População } & \multirow{2}{*}{$\begin{array}{l}\text { Mudanças } \\
\text { demográ- } \\
\text { ficas }\end{array}$} & $\begin{array}{l}\text { Taxa de crescimento da } \\
\text { população }\end{array}$ & & $\mathrm{X}$ & \\
\hline & & $\begin{array}{l}\text { População em moradias não } \\
\text { regularizadas ou irregulares. }\end{array}$ & $\mathrm{X}$ & & \\
\hline
\end{tabular}




\begin{tabular}{|c|c|c|c|c|c|}
\hline \multirow{2}{*}{$\begin{array}{l}\text { Vertente } \\
\text { Principal }\end{array}$} & \multirow[t]{2}{*}{ Elementos } & \multirow[t]{2}{*}{ Indicador } & \multicolumn{3}{|c|}{ Grau de Ocorrência } \\
\hline & & & Alta & Média & Baixa \\
\hline \multicolumn{6}{|c|}{ SUSTENTABILIDADE AMBIENTAL } \\
\hline Atmosfera & $\begin{array}{l}\text { Mudança } \\
\text { climática }\end{array}$ & $\begin{array}{l}\text { Emissão de gases que contri- } \\
\text { buem para o efeito estufa }\end{array}$ & & & $\mathrm{X}$ \\
\hline \multirow{7}{*}{ Terra } & \multirow[t]{3}{*}{ Agricultura } & $\begin{array}{l}\text { Área de cultura agrícola } \\
\text { permanente e de terras } \\
\text { agricultáveis }\end{array}$ & $\mathrm{X}$ & & \\
\hline & & Uso de fertilizantes & $\mathrm{X}$ & & \\
\hline & & Uso de agrotóxicos & & & $\mathrm{X}$ \\
\hline & \multirow[t]{2}{*}{ Florestas } & Área permanente de floresta & $\mathrm{X}$ & & \\
\hline & & $\begin{array}{l}\text { Revestimento de mata } \\
\text { intensiva }\end{array}$ & & $\mathrm{X}$ & \\
\hline & $\begin{array}{l}\text { Desertifica- } \\
\text { ção }\end{array}$ & Área desertificada & & & $\mathrm{X}$ \\
\hline & $\begin{array}{l}\text { Urbaniza- } \\
\text { ção }\end{array}$ & $\begin{array}{l}\text { Área de urbanização legal } \\
\text { e ilegal }\end{array}$ & & $\mathrm{X}$ & \\
\hline \multirow{6}{*}{$\begin{array}{l}\text { Rios e } \\
\text { Igarapés }\end{array}$} & \multirow[t]{2}{*}{ Zona de rio } & $\begin{array}{l}\text { Concentração de algas em } \\
\text { águas }\end{array}$ & & & $\mathrm{X}$ \\
\hline & & $\begin{array}{l}\text { Percentagem da população } \\
\text { total vivendo em zonas de } \\
\text { rios }\end{array}$ & $\mathrm{X}$ & & \\
\hline & Pesqueiros & $\begin{array}{l}\text { Captura anual de espécies de } \\
\text { maior interesse comercial }\end{array}$ & & & $\mathrm{X}$ \\
\hline & $\begin{array}{l}\text { Quantidade } \\
\text { de água }\end{array}$ & $\begin{array}{l}\text { Percentagem de fornecimen- } \\
\text { to anual de água subterrânea } \\
\text { e de superfície por disponibi- } \\
\text { lidade total de água }\end{array}$ & $\mathrm{X}$ & & \\
\hline & \multirow[t]{2}{*}{$\begin{array}{l}\text { Qualidade } \\
\text { da água }\end{array}$} & $\begin{array}{l}\text { Demanda Bioquímica por } \\
\text { oxigênio (BOD) em corpos } \\
\text { d'água }\end{array}$ & $\mathrm{X}$ & & \\
\hline & & $\begin{array}{l}\text { Concentração de coliformes } \\
\text { fecais em água potável }\end{array}$ & & & $\mathrm{X}$ \\
\hline \multirow{3}{*}{$\begin{array}{l}\text { Biodivers- } \\
\text { idade }\end{array}$} & Ecosistemas & Areas protegidas & $\mathrm{X}$ & & \\
\hline & & $\begin{array}{l}\text { Percentagem da área protegi- } \\
\text { da por área total }\end{array}$ & $\mathrm{X}$ & & \\
\hline & Espécies & $\begin{array}{l}\text { Abundância das espécies } \\
\text { protegidas }\end{array}$ & & & $\mathrm{X}$ \\
\hline
\end{tabular}




\begin{tabular}{|c|c|c|c|c|c|}
\hline \multirow{3}{*}{$\begin{array}{l}\text { Vertente } \\
\text { Principal }\end{array}$} & \multirow{3}{*}{ Elementos } & \multicolumn{4}{|c|}{ Quadro 1 - Conclusão } \\
\hline & & \multirow[t]{2}{*}{ Indicador } & \multicolumn{3}{|c|}{ Grau de Ocorrência } \\
\hline & & & Alta & Média & Baixa \\
\hline \multicolumn{6}{|c|}{ SUSTENTABILIDADE ECONÔMICA } \\
\hline \multirow{9}{*}{$\begin{array}{l}\text { Estrutura } \\
\text { Econômica }\end{array}$} & \multirow{5}{*}{$\begin{array}{l}\text { Nível de } \\
\text { Renda }\end{array}$} & Renda per capita & & $\mathrm{X}$ & \\
\hline & & Investimento em poupança & & & $\mathrm{X}$ \\
\hline & & $\begin{array}{l}\text { Investimento em Inversões } \\
\text { Fixas Agricultura, Pecuária, } \\
\text { etc.) }\end{array}$ & $\mathrm{X}$ & & \\
\hline & & $\begin{array}{l}\text { Investimento em custeio } \\
\text { (Agricultura, pecuária, etc.) }\end{array}$ & $\mathrm{X}$ & & \\
\hline & & Investimento em lazer e etc. & $\mathrm{X}$ & & \\
\hline & Comércio & $\begin{array}{l}\text { Quantidade de Estabeleci- } \\
\text { mentos }\end{array}$ & $\mathrm{X}$ & & \\
\hline & Serviços & $\begin{array}{l}\text { Quantidade de Estabeleci- } \\
\text { mentos }\end{array}$ & & & $\mathrm{X}$ \\
\hline & \multirow{2}{*}{$\begin{array}{c}\text { Sistema } \\
\text { Financeiro }\end{array}$} & Agencia Bancária & & & $\mathrm{X}$ \\
\hline & & $\begin{array}{l}\text { Posto de atendimento } \\
\text { avançado }\end{array}$ & & & $\mathrm{X}$ \\
\hline \multirow{7}{*}{$\begin{array}{c}\text { Consumo e } \\
\text { padrões de } \\
\text { produção }\end{array}$} & $\begin{array}{l}\text { Matéria } \\
\text { primas }\end{array}$ & $\begin{array}{l}\text { Intensidade de consumo das } \\
\text { Matérias Primas }\end{array}$ & & & $\mathrm{X}$ \\
\hline & \multirow[t]{3}{*}{$\begin{array}{l}\text { Uso de } \\
\text { Energia }\end{array}$} & $\begin{array}{l}\text { Consumo anual per capita de } \\
\text { energia }\end{array}$ & & $\mathrm{X}$ & \\
\hline & & $\begin{array}{l}\text { Investimento em ações de } \\
\text { energia renováveis e não- } \\
\text {-renováveis }\end{array}$ & & & $\mathrm{X}$ \\
\hline & & $\begin{array}{l}\text { Intensidade do uso da } \\
\text { energia }\end{array}$ & & & $\mathrm{X}$ \\
\hline & \multirow[t]{3}{*}{$\begin{array}{l}\text { Gerencia- } \\
\text { mento dos } \\
\text { efluentes }\end{array}$} & $\begin{array}{l}\text { Gerenciamento do lixo } \\
\text { industrial e outros resíduos } \\
\text { urbanos }\end{array}$ & & & $\mathrm{X}$ \\
\hline & & Geração de lixo perigoso & & & $\mathrm{X}$ \\
\hline & & Geração de lixo radioativo & & & $\mathrm{X}$ \\
\hline
\end{tabular}

Fonte: Elaborado pelos autores, dados extraídos da pesquisa de campo (2012).

No quadro 1 observa-se os dados coletados de acordo com 03 (três) dimensões: sustentabilidade social, ambiental e econômica. Nessas dimensões identificaram-se as vertentes principais, elementos e indicadores com o grau de ocorrência nas seguintes escalas de 01 a 10: de 7 a 10 considera alta, de 4 a 6 a média e de 0 a 3 como baixas, para informar o grau de sustentabilidade dos indicadores, encontrados com as 31 (trinta e uma) familias pesquisadas e, assim se propor ações estratégicas que venham a contribuir com a execução das atividades dimensionadas nesses programas. 
A análise dos resultados iniciou-se pela dimensão social, na vertente moradia. $O$ gráfico 01 espelha alguns elementos e indicadores da vertente equidade, que possibilitam enfatizar uma análise exógena e ao mesmo tempo endógena do local, em uma escala de ocorrência determinada (alta, média e baixa), demonstrando que as dimensões sociais, ambientais e econômicas não foram contempladas na sua totalidade. $\mathrm{Na}$ dimensão social se destacam as vertentes: equidade; saúde; educação; moradia; segurança; e população, a qual apresenta a performance do Reassentamento Novo Engenho Velho.

Gráfico 01: Vertente principal Equidade

\section{Equidade}

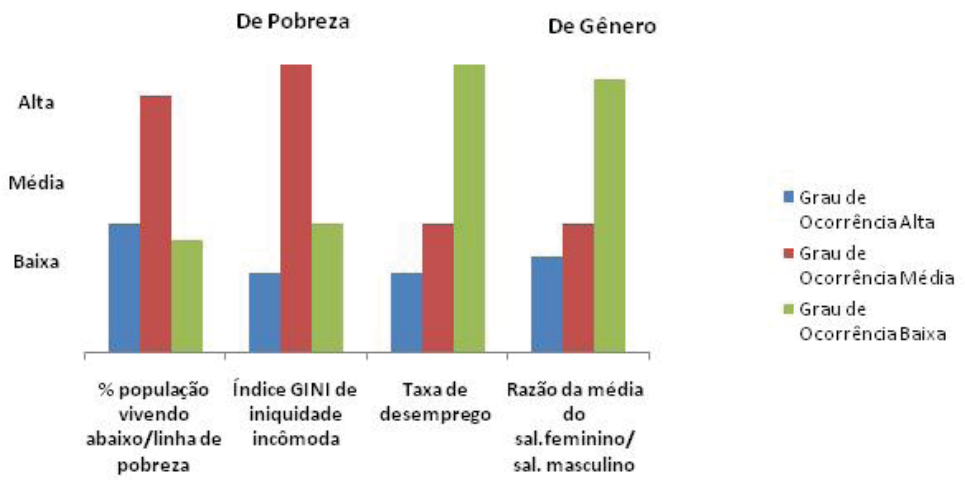

Fonte: Elaborado pelos autores, dados extraídos da pesquisa de campo (2012).

Analiticamente a vertente equidade expressa a sua significância no papel de informar em que condições de dignidade vivem essas famílias percebidas por esses projetos. No elemento abaixo da linha da pobreza, considerando o universo pesquisado, observa-se que a metade necessita de um suporte educacional por meio de capacitação que promovam o conhecimento - aprendizado de novas habilidades ou melhorar as que já existem, para serem aproveitados na execução do projeto e proporcionar uma visão mais ampla, objetivando o aproveitamento de novas oportunidades e ocupações que surgem com o crescimento econômico.

Mas, por outro lado, estabelecendo uma relação com o índice Gini, que mede a concentração ou desigualdade entre os mais ricos e os mais pobres, identificou-se um diferencial em relação à metade mais baixa, contemplada com incentivo do consórcio para melhoria 
de moradia (aquisição de casas), mas também com indenizações

financeiras possibilitando uma performance maior em termos de concentração de renda. Esse aspecto é um fator de preocupação, pois a administração desses recursos ou nova condição de vida induz a uma habilidade gerencial não existente nos seus perfis.

Esses dados confirmam o resultado do indicador taxa de desemprego, que registrou um grau de ocorrência baixo, refletindo ainda mais a necessidade de qualificação para fazer frente à alta demanda por mão de obra qualificada.

A participação da mulher centra-se somente nos afazeres domésticos o que indica uma ocorrência baixa na relação salário médio feminino/salário médio masculino, dificultando ainda mais o aproveitamento dessas oportunidades. É necessário observar e promover a elevação desse grau de ocorrência por meio de um complexo de medidas educacionais que venham a induzir a mudanças de paradigmas.

A saúde nos elementos: nutrição de crianças; mortalidade; saneamento básico; água potável; e distribuição da atenção à saúde registrou um grau de ocorrência alto para todos os seus indicadores, o que significa dizer, que o reassentamento necessita de uma ação proativa dos órgãos gerenciadores de políticas públicas para que se promova a redução desses fatores.

Nesse contexto, a educação como vertente principal, é o fator central para solução desses pontos de estrangulamento. O gráfico 2 apresenta um panorama local considerando os elementos dimensionados e relevantes com seus respectivos indicadores.

Gráfico 2: Vertente principal Educação

\section{Educação}

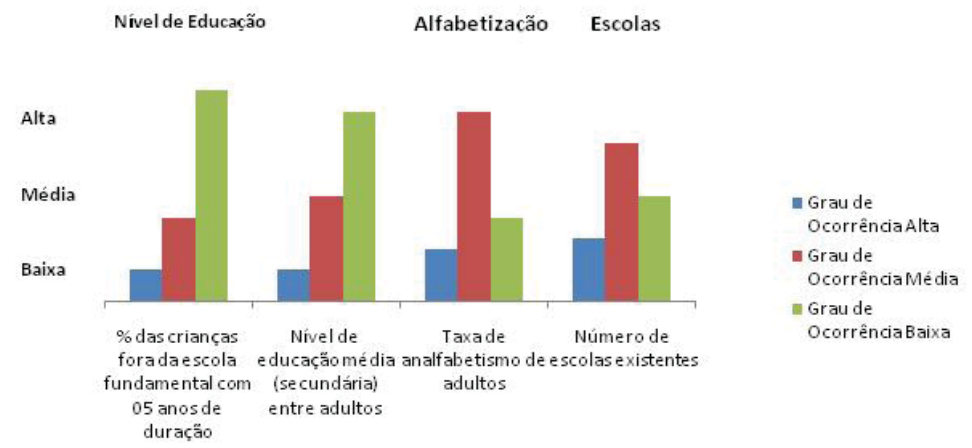

Fonte: Elaborado pelos autores, dados extraídos da pesquisa de campo (2012). 
Os elementos nível de educação, alfabetização e escolas por meio de seus indicadores refletem a realidade do reassentamento quando se destaca o percentual de crianças vivendo fora da escola fundamental com 05 anos de duração é altamente baixo, pressupondo a inexistência de infraestrutura escolar nessa faixa etária e a dificuldade de acesso em virtude da distância e de meios de locomoção ou transportes adequados e de baixo custo às famílias.

A mesma ocorrência baixa é verificada no nível de educação média entre adultos e, pressupõe que esse grau esteja relacionado à ausência de escolas no local, levando muitos adultos a falta de acesso à rede de ensino. Além disso, observa-se a questão da disposição a enfrentar os bancos das escolas, pois não existe um trabalho de motivação que os levem a buscar novos conhecimentos e aprendizados.

Nesses casos, se justifica ainda mais a necessidade de se induzir políticas públicas voltadas à formação de recursos humanos, como é o caso dos Laboratório Organizacional de Terreno de Capacitação Massiva, citado por Moraes (2001), que se apresenta como uma alternativa plausível de qualificação profissional para o emprego ou mais propriamente, à ocupação da mão de obra em atividades produtivas geradoras de renda e, passível de resolver a equação qualificação - emprego.

$\mathrm{Na}$ vertente segurança, no indicador crime, o grau de ocorrência foi médio, pois apesar do Reassentamento ter sido implantado há pouco tempo, a proximidade com construção da UHE e, consequentemente com os operários ou trabalhadores, tem trazido sérios transtornos ao local, registrando-se algumas ocorrências. Esse fator de proximidade influencia o indicador: taxa de crescimento da população - promovendo um grau de ocorrência médio, o que se pressupõe que esses operários migrantes vêm influenciando essa taxa e que se precisa estudar com mais ênfase os reflexos desse fenômeno e informar à sociedade.

Outro fato importante dessa vertente é o indicador população em moradia não regularizado ou irregular, pois se verificou um grau de ocorrência alta, pois a comunidade encontra-se em fase de estruturação e os órgãos de apoio ainda estão em processo de tramitação da regularização fundiária do reassentamento.

REVISTA GRIFOS - N. 32/33 - 2012 
Deflagrando-se a regularização, a dimensão ambiental entra em análise como prioridade nas observações considerando suas vertentes principais. As áreas produtivas dos quintais agroecológicos, com grau de ocorrência baixo no elemento mudanças climáticas e o indicador emissão de gases, se alavancam, pois oportuniza a essas famílias trabalharem com a terra de forma ambientalmente correta através do uso dos meios necessários de produção que venham os fortalecer tais como: terra, capital, trabalho e tecnologias. O gráfico 3 configura as várias formas de uso da terra no reassentamento.

Gráfico 3: Vertente principal Terra

\section{Terra}

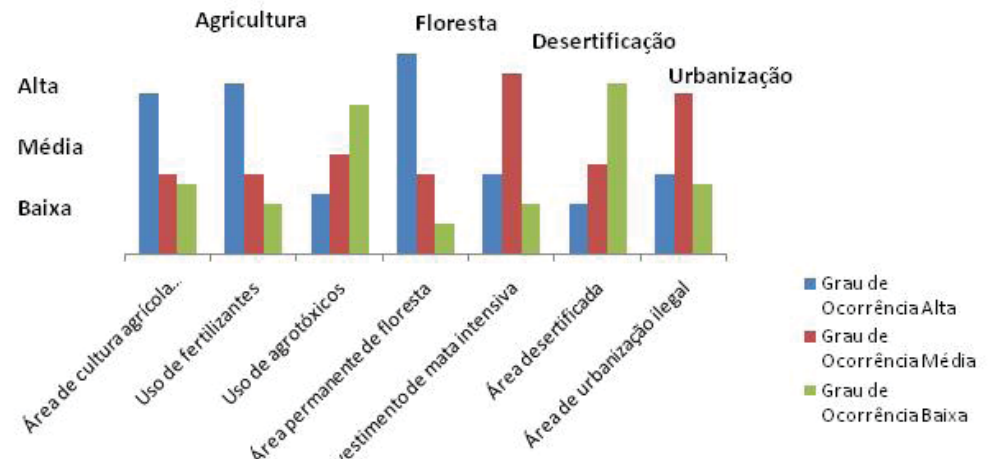

Fonte: Elaborado pelos autores, dados extraídos da pesquisa de campo (2012).

A área de cultura agrícola e de terras agricultáveis registra um grau de ocorrência alto, pois 50\% das famílias possuem lotes de produção com área média de 3,0 ha e, concomitantemente, utilizam fertilizantes registrando alto grau de ocorrência. Por vários fatores limitantes não são utilizados agrotóxico ou produtos químicos. Um dos fatores é o o baixo nível de renda já mencionado anteriormente e que será tratado de forma mais analítica a seguir.

O gráfico 4 mostra a ocorrência da vertente principal Rios e Igarapés e seus elementos zona de rios, pesqueiros, quantidade de água e qualidade da água. 
Gráfico 4: Vertente principal Rios e Igarapés.

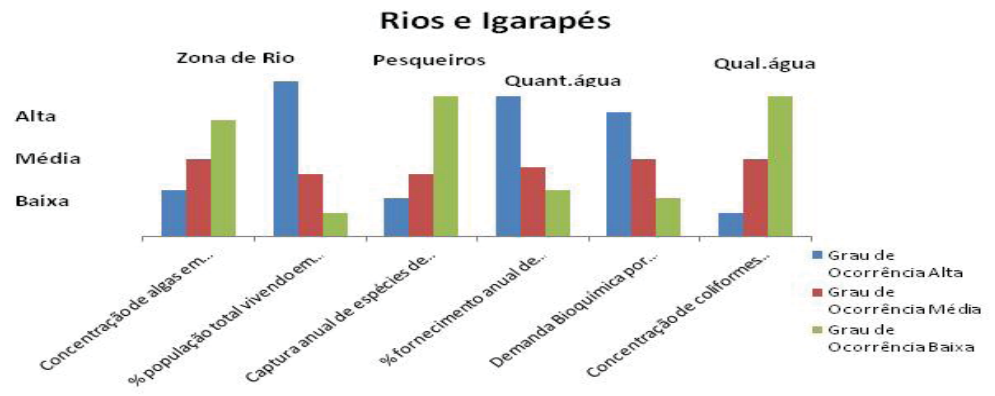

Fonte: Elaborado pelos autores, dados extraídos da pesquisa de campo (2012).

$\mathrm{Na}$ vertente Rios e Igarapés, os indicadores com grau de ocorrência baixo foram: concentração de algas em água, captura anual de espécies de maior interesse comercial e concentração de coliformes fecais em água potável. Já os indicadores: percentual da população vivendo em zonas de rios, fornecimento anual de água subterrânea e demanda bioquímica tiveram grau de ocorrência alto por serem constantes e representativos na dimensão ambiental, e necessários à sobrevivência das famílias.

Observando o quadro da vertente biodiversidade, seus elementos e indicadores também visualizados apresentam um grau de ocorrência baixa, pontuados no gráfico 5 .

Gráfico 5: Vertente principal Biodiversidade.

\section{Biodiversidade}

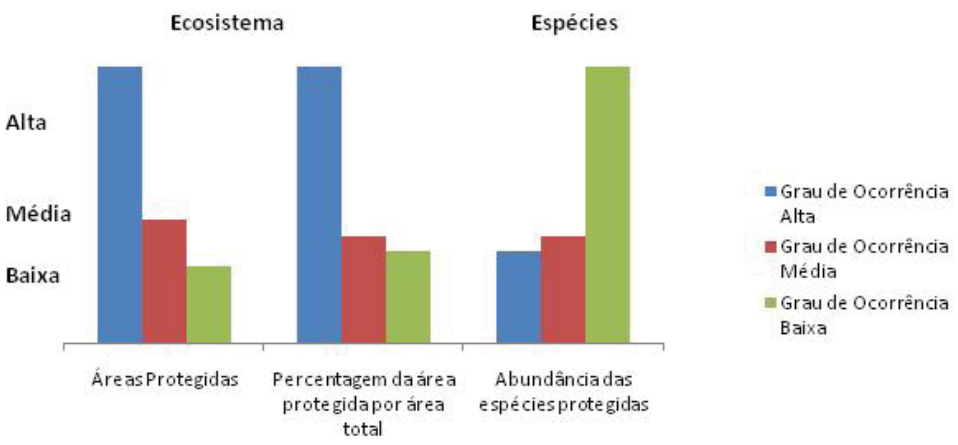

Fonte: Elaborado pelos autores, dados extraídos da pesquisa de campo (2012).

No entanto, o elemento ecossistema destaca dois indicadores significativos para informar se realmente as áreas estão protegidas, 
constatando-se um grau de ocorrência alto e, caracterizando-se como área ambientalmente sustentável. Nessa direção observase o contrário para o elemento espécie animal, pois se registra um grau de ocorrência baixo, significando que na área protegida do reassentamento as populações da fauna silvestre se extinguiram, não retornaram e não foi realizada nenhuma ação para atrair o seu retorno.

Outra reflexão sobre o reassentamento centra-se na dimensão econômica em que se pontuam os elementos: nível de renda, comércio, serviços e sistema financeiro com seus respectivos indicadores, como é demonstrado no Gráfico 6.

Gráfico 6: Vertente principal Estrutura Econômica.

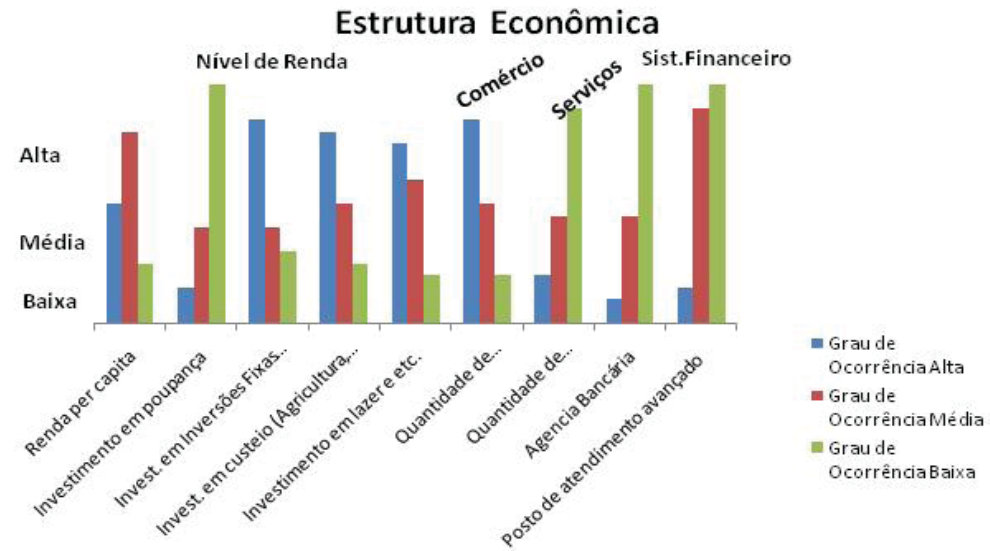

Fonte: Elaborado pelos autores, dados extraídos da pesquisa de campo (2012).

As famílias do reassentamento registram uma renda per capita em grau de ocorrência média, demonstrando que existem duas classes: uma com renda per capita baixa e outra alta, corroborando com o que já foi demonstrado na vertente equidade. Essas famílias apresentam um baixo grau de investimento em poupança, mas nas inversões fixas o grau de ocorrência é alto, significando que investem em imobilizados para o trabalho nos quintais agroecológicos e até mesmo em infraestrutura de construção. Entretanto, ressalta-se que essas construções originaram-se de indenizações do consórcio na promoção do reassentamento. Verifica-se que as inversões nos quintais, ainda não são externadas e visualizadas caracterizando baixo ou nenhum investimento.

O que se pressupõe é que a outra metade das famílias obteve renda por meio das indenizações de áreas antes habitadas 
e desapropriadas depois pelo consórcio Santo Antônio, e está investindo em ativo fixo. Isso somado às moradias doadas espelha realmente o resultado da pesquisa que demonstra um alto grau de ocorrência, justificando-o. A mesma análise se faz aos indicadores: investimentos em custeio e investimento em lazer.

Observa-se no reassentamento uma tendência ao comércio, pois resultou em um alto grau de ocorrência. Todavia, são comércios pequenos, os chamados mercantis (mercearias) informais de suporte às famílias. $\mathrm{O}$ segmento de serviços demonstra um baixo grau de ocorrência espelhando e confirmando que essas famílias não têm qualificação necessária a prestação de serviços de qualquer natureza formal, onde possam agregar valor. Defende-se que por meio de um processo de capacitação massiva isso possa se deflagrar e apresentar em um futuro próximo outro quadro de desenvolvimento local. Já o elemento sistema financeiro espelha um baixo grau de ocorrência traduzindo em uma total inexistência dos indicadores: agências bancárias e postos de atendimento avançado.

As formas de consumo do reassentamento, além de englobar os já citados anteriormente, abrangem também a vertente consumo e padrões de produção, seus elementos e indicadores como são apresentados no gráfico 7 :

Gráfico 7: Vertente principal Consumo e Padrões de Produção.

\section{Consumo e padrões de produção}

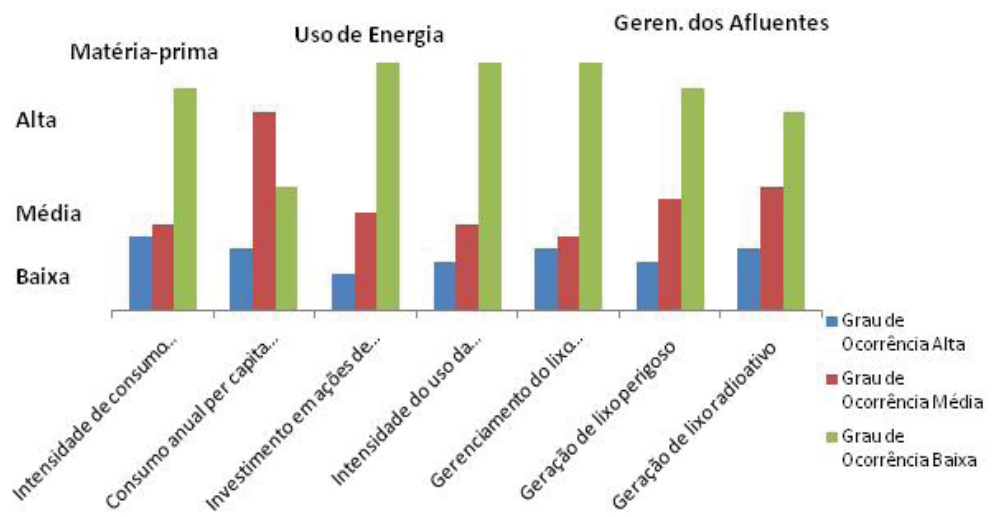

Fonte: Elaborado pelos autores, dados extraídos da pesquisa de campo (2012).

Em análise geral essa vertente reflete um quadro de similaridade nos graus de ocorrência dos indicadores avaliados, destacando-se o baixo grau de ocorrência para a maioria das formas de consumo e de padrões de produção. Nota-se um 
destaque somente para o indicador consumo anual per capita, pois

resultou em um médio grau de ocorrência no reassentamento. Isso se caracteriza pelo fato de ser um reassentamento novo, que está sendo estruturado no momento por meio do apoio do projeto de Acompanhamento Técnico e Extensão Rural-ATER.

Exalta-se mais uma vez, os LOT de capacitação massiva como forma sustentável de formação de recursos humanos, que possibilitaria melhorar o desempenho das famílias do reassentamento, no que tange aos fatores que levam a empregabilidade local e, ao mesmo tempo torná-los proativos no empreendedorismo para alavancagem de seus negócios e alcançarem uma vida mais digna.

Nessa mesma direção,énecessário utilizaros resultados da pesquisa levando em consideração as dimensões, seus elementos e indicadores para propor medidas precisas que induzam ao desenvolvimento sustentável do Reassentamento Novo Engenho Velho.

$\mathrm{O}$ resultado da pesquisa evidenciou o reconhecimento da melhoria da infraestrutura antes inexistente. Entretanto, no novo local de moradia, a realidade é outra, pois não há mais as diversificadas fontes de renda e a falta de sua principal fonte de alimento, o rio. As famílias eram formadas em sua maioria por agricultores, extrativistas e pescadores que exploravam economicamente as áreas de várzea e cultivavam também em terra firme.

\section{Considerações finais}

A partir das análises dos dados coletados, tendo como base as 03 (três) dimensões sustentabilidade social, ambiental e econômica, identificando pelas vertentes Equidade, Educação, Terra, Rios e Igarapés, Biodiversidade, Estrutura Econômica, Consumo e Padrão de Produção, foi possível apontar a necessidade de qualificação profissional dos moradores do Novo Engenho Velho/RO. A falta desta qualificação faz com que os moradores desta localidade deixem de realizar atividades que produzam renda sustentável.

Os moradores da localidade Novo Engenho Velho são ribeirinhos que foram remanejados para uma área de terra que não tem subsistência produtiva natural, longe da sua principal atividade econômica de sobrevivência, que é a pesca.

Diante deste quadro o artigo mostra a necessidade de se aplicar uma metodologia de capacitação profissional para esses 
moradores remanejados. A capacitação sugerida neste estudo e que irá atender a todos, qualificando-os para as novas atividades, é a Capacitação Massiva.

A metodologia de Capacitação Massiva atende aos requisitos de uma ação efetiva para o desenvolvimento local, ajudando os seus participantes a gerar emprego e renda, contrapondo-se a projetos de grande porte, onde a comunidade sofre ações geradas em seu meio.

Os moradores do Reassentamento Novo Engenho Velho tem se mostrado insatisfeitos quanto ao local para o qual esta comunidade foi remanejada, mostrando assim a falta de discussão do Consórcio Santo Antônio Energia, no processo de negociação do deslocamento. Os moradores da agrovila deixaram atividades produtivas originais como a pesca e o consórcio das usinas não apresentaram alternativas para a comunidade, evidenciando assim a importância da Capacitação Massiva para os reassentados.

Nos resultados apresentadas das vertentes principais bem como observada a de Equidade nos seus elementos: de pobreza e de Gênero, mostra pelos resultados de seus indicadores que a comunidade reassentada vivencia com índice médio de pobreza - pela indenização que receberam - mas, com alto índice de desemprego, principalmente em se tratando de gênero.

\section{Referências}

ARAÚJO, S. L. La Autogestión como Instrumento de Inclusión Social en el Contexto de la Economia Globalizada, 2002. Disponível em: <http:// www.workandskills.ch/downloads/Lopes.pdf> Acesso em: 13. mar. 2011.

COELHO, Simone Costa Tavares, Parecer Técnico sobre Projetos: Gestão e Políticas Públicas Sociais, 2007.

MilitÃO, J. S. L. T.; SILVEIRA, A. S. P.; VALLE, C. A. Programa Regional de reforma Agrária de Rondônia. INCRA, 2005.

MORET, Artur de Souza. Parecer Sobre o Estudo de Impacto Ambiental do Projeto para Aproveitamento Hidrelétrico de Santo Antônio e Jirau no Rio Madeira. 2007.

MORAIS, C.S. Já Estamos na Camuflada Guerra Civil do Desemprego. Primeira Versão, v. 67, 2001. Disponível em: <http://www.unir. br/ primeira/artigo67.html>. Acesso em: 05. abr. 2011. 
PEREIRA, R.B. Voz da Terra - Assis-SP.2002. Disponível em: <http://

www.ajorb.com.br/vt-ensino.htm> Acesso em: 07. mar.2011.

SANTOS, Milton. A Natureza do Espaço: Técnica e Tempo, Razão e Emoção. SP: Universidade de São Paulo 2002.

SIENA, O. Método para avaliar progresso em direção ao desenvolvimento sustentável. Universidade Federal de Santa Catarina. Tese (Doutorado em Engenharia de produção). UFSC, Centro Tecnológico (CTC), Programa de pós-graduação em engenharia de produção (PPGEP). Florianópolis: UFSC, 2002.

SIENA, Osmar. Metodologia da pesquisa científica: elementos para elaboração e apresentação de trabalhos acadêmicos. Porto Velho: UNIR, 2007.

VIRGULINO, Amarildo Pinheiro. Gestão Integrada Sustentada de Sistemas Agroflorestais com Cacaueiro: Um Estudo do Projeto de Assentamento Dirigido Burareiro. Dissertação de Mestrado em Desenvolvimento Regional e Meio Ambiente da Fundação Universidade Federal de Rondônia, 2008.

\title{
CONSEQUENCES OFRESETTLEMENTINTHESURROUNDINGS OFSANTO ANTÔNIOHYDROELECTRIC:THE CASEOFTHE RESETTLEMENTNOVO ENGENHOVELHOINPORTOVELHO/RO-BRAZIL
}

\begin{abstract}
This article presents the consequences of resettlement Novo Engenho Velho in the State of Rondônia, in the vicinity of the construction of the plant in Santo Antonio, offering a methodology for training of human resources for the quality of life of the settlers. The paper conducts a discussion about territory as spatial configuration, and local occupancy of 31 families who were relocated from their dwelling riverside community - forming a Agrovila. The survey was developed from the case study. It was applied semi-structured questionnaire with closed questions, which got $100 \%$ return of the interviews, and the instrument was divided into 03 dimensions of sustainability: social, environmental and economic. Among the findings, which stood out among the three dimensions was the social sustainability, with relevant degree, presented by the indicator unemployment rate, thus justifying the need to qualify and train for this community deals with labor income that will arise in new occupations. As a solution to the identified consequences is proposed methodology Massive Training with development activities relevant to the region.
\end{abstract}

Keywords: Resettlement. Hydroelectric Plant. Territory. Methodology Training Massive. 